\title{
LOS SUPUESTOS DE RESTITUCIÓN DE GANANCIAS ILÍCITAS EN EL DERECHO PRIVADO CHILENO
}

\author{
DISGORGEMENT DAMAGES CASES IN CHILEAN PRIVATE LAW
}

\begin{abstract}
Alberto Pino Emhart*
RESUMEN: Este trabajo identifica los supuestos de restitución de ganancias ilícitas en el contexto del derecho privado chileno. Se trata de acciones restitutorias desarrolladas principalmente por la doctrina alemana y anglosajona, sobre aquellas ganancias que han sido obtenidas ilícitamente, ya sea provenientes de una invasión o utilización de propiedad ajena, del incumplimiento de obligaciones fiduciarias, o de un ilícito civil extracontractual. El objetivo del artículo es señalar, a partir de las características de esta acción delineadas por el derecho comparado, aquellas hipótesis que han sido acogidas expresamente en el derecho privado chileno, de modo tal de poder analizar adecuadamente algunos problemas comunes que se derivan de su caracterización como restitución de ganancias ilícitas.

Palabras clave: Restitución de ganancias, enriquecimiento injustificado, derecho de la restitución, responsabilidad extracontractual.

ABSTRACT: This work identifies the cases of disgorgement damages in the context of Chilean private law. These are restitutionary damages developed mainly by German and English scholars, to recover wrongful gains, obtained as a consequence of an infringement or invasion to property rights, a breach of fiduciary duties, or a tort. The objective of the paper is to identify, from the perspective of the main features clarified in comparative law, the cases established expressly by positive law in Chilean private law, in order to be able to adequately analyze some common problems that arise as a consequence of being qualified as disgorgement damages.
\end{abstract}

Keywords: Account of profits, unjust enrichment, law of restitution, tort law.

\section{INTRODUCCIÓN}

La restitución de ganancias ilícitas es un remedio ${ }^{1}$ de carácter restitutorio que persigue la restitución de las ganancias obtenidas por quien ha cometido un ilícito civil. En el derecho privado chileno, existen hipótesis legisladas que son asimilables a esta acción. En este sentido, el objetivo de este trabajo es identificar, a partir de las características de esta acción delineadas por el derecho comparado, aquellas hipótesis que han sido acogidas expresamente en el derecho privado chileno. Con ello, se pretende abrir el estudio de estos

* Doctor en Derecho, University of Oxford. Profesor Asistente, Universidad Adolfo Ibáñez, Chile. Dirección postal: Av. Diagonal Las Torres 2640, Oficina 218-B, Peñalolén, Santiago. Dirección electrónica: alberto.pino@ uai.cl. Este trabajo forma parte del proyecto de Fondos Internos de Apoyo a la Investigación de la Universidad Adolfo Ibáñez 2017, y del proyecto Fondecyt de Iniciación № 11170398 "La restitución de ganancias ilícitas en el derecho privado chileno", del que el autor es investigador responsable.

1 Entiendo por remedio "toda medida de protección que ofrece el ordenamiento jurídico a un sujeto en una determinada situación, frente a la lesión de un interés”. Morales (2011) p. 402. 
grupos de casos desde la perspectiva del derecho de la restitución, de manera tal de otorgar respuestas a problemas y preguntas que no han sido estudiadas con suficiente detención por la doctrina chilena.

El artículo se estructura sobre la base de una segunda sección, en la cual se explican las principales características de la acción de restitución de ganancias ilícitas desarrolladas por la doctrina alemana y anglosajona, y el lugar que ocupa dentro del derecho de las obligaciones. Junto con ello, se enuncian en general las hipótesis reconocidas en el derecho comparado, y las principales dificultades a las que se enfrentan. La tercera sección constituye la más importante del trabajo, e identifica cuatro grupos de casos en los cuales el derecho privado chileno contempla expresamente acciones de restitución de ganancias ilícitas. Una cuarta sección da cuenta de los principales problemas y discusiones que deben enfrentarse, una vez aceptada la clasificación de estas hipótesis como restitución de ganancias. Finalmente, en la quinta sección se indican las conclusiones.

\section{LA RESTITUCIÓN DE GANANCIAS ILÍCITAS EN EL DERECHO DE LAS OBLIGACIONES. UNA APROXIMACIÓN A LA DOCTRINA ALEMANA Y ANGLOSAJONA}

La doctrina chilena ha reconocido por largo tiempo la existencia del enriquecimiento injustificado en el ordenamiento jurídico nacional ${ }^{2}$, ya sea como un principio para la justificación de normas jurídicas, como principio orientador para la interpretación de disposiciones del Código Civil, o como mecanismo de integración para la resolución de lagunas legales. Si bien gran parte de la doctrina ha planteado que este principio constituiría una fuente autónoma de obligaciones ${ }^{3}$, otra parte de ella y en ocasiones, los tribunales chilenos, no le reconocen tal valor ${ }^{4}$.

El Código Civil chileno (en adelante CC) sigue la tendencia generalizada de los Códigos del siglo XIX al no contemplar una norma expresa y general que acoja el enriquecimiento injustificado como principio o fuente autónoma de obligaciones, tendencia que comienza a revertirse en el caso de los códigos que se dictan a partir del siglo $\mathrm{XX}^{5}$. Puede citarse también el caso reciente del nuevo Código Civil argentino (art. 1794) y el artículo 1303 del Código Civil francés tras la reforma de 2016. La tendencia de los códigos más recientes parece, entonces, ser la de consagrar expresamente el enriquecimiento injustificado como fuente autónoma de obligaciones ${ }^{6}$.

Precursor de esta tendencia es el Código Civil alemán, el cual en el \$ 812(1) estableció el principio general del enriquecimiento injustificado: "El que ha recibido algo por medio de la prestación de otro o a expensas de otro de cualquier otra forma sin una base jurí-

\footnotetext{
2 Véase, entre otros, FueYo (1990), Peñailillo (1996).

3 Abeliuk (2008) pp. 54-55, Peñailillo (2003) pp. 104-118.

4 Barrientos (2016) pp. 311-314; Sociedad Corral y Alcaino con Codelco Chile (2015) cons. $12^{\circ}$.

5 Peñailillo (1996) pp. 31-32.

6 La misma tendencia puede apreciarse en los proyectos de armonización del derecho privado europeo, particularmente en el Libro VII del Draft Common Frame of Reference de 2009. Véase Zumaquero (2017) pp. 4-53.
} 
dica, es obligado a restituirlo". Sin embargo, la formulación de esta regla general no parece resolver todos los problemas. ¿En qué sentido debe entenderse el recibir un beneficio "a expensas de otro"? ¿Qué significa que el enriquecimiento no tenga una justificación o base jurídica? Renunciando a la posibilidad de plantear una fórmula general que cubra todos los casos, la doctrina alemana tradicionalmente siguiendo al jurista Ernst von Caemmerer ${ }^{7}$ ha elaborado una tipología o grupos de supuestos en los cuales al demandante se le otorga una acción de enriquecimiento injustificado:

(1) Demandante que realiza un servicio al demandado que no tenía una base jurídica, en el sentido que el objetivo perseguido por el demandante no se cumplió.

(2) Demandado que realiza una intromisión (Eingriff) en un derecho de propiedad del demandante.

(3) Demandante que incurre en gastos que mejoraron la propiedad del demandado.

(4) Demandante que paga una deuda ajena y demanda restitución en contra del demandado.

Nos concentraremos aquí en la segunda de estas hipótesis: la intromisión en derecho ajeno. En estos supuestos, el enriquecimiento se ha producido como consecuencia de la interferencia o intromisión en los derechos de otro. De inmediato resaltan tres importantes características: En primer lugar, la hipótesis restitutoria surge, al menos en esta formulación, asociada al derecho de propiedad del demandante. Es la invasión o intromisión en el derecho de propiedad lo que faculta al demandante para interponer la acción restitutoria, cuyo objeto será la restitución de los beneficios obtenidos a expensas de esta intromisión en su derecho de dominio. En segundo lugar, la acción no requiere grado alguno de imputación subjetiva del demandado para que sea procedente; es suficiente la interferencia en el derecho de propiedad. Y por último, como advierte Zimmermann, esta categoría de von Caemmerer no puede aplicarse sin responder primero la pregunta de quién era el titular del derecho que fue objeto de la intromisión ${ }^{8}$. La respuesta de von Caemmerer radica en la concepción misma del derecho de propiedad: es una atribución exclusiva del propietario el usar, gozar y disponer de la cosa, por lo cual la utilización por parte de un tercero de la cosa objeto de dominio es injustificada y, por tanto, debe restituir los beneficios que haya obtenido?

Por otra parte, esta hipótesis restitutoria ha sido desarrollada ampliamente en el derecho anglosajón, especialmente durante los últimos 30 años. A partir del trabajo de Peter Birks, la doctrina inglesa ha desarrollado la noción del derecho de la restitución (Law of Restitution), categoría general a la cual pertenecería el enriquecimiento injustificado. En este sentido, Birks define la restitución como "la respuesta que consiste en provocar que una persona entregue a otro un enriquecimiento que recibió a sus expensas o su valor en dinero" ${ }^{10}$. Sin embargo, con posterioridad otros autores (y el propio Birks) han planteado

\footnotetext{
7 VON CAEMMERER (1968) pp. 370-392.

8 ZimMERMANn (1990) p. 889.

9 von Caemmerer (1968) p. 378.

10 Birks (1985) p. 13.
} 
que el derecho de la restitución sería un evento multi-causativo que se ocupa de arrebatarle al demandado las ganancias obtenidas y no de indemnizar los perjuicios a las víctimas ${ }^{11}$. Bajo esta concepción, el enriquecimiento injustificado sería la especie y el derecho de la restitución el género ${ }^{12}$. Siguiendo la formulación clásica de Pomponio en el Digesto ${ }^{13}$, Birks sostiene que la obligación de restituir puede originarse a partir de dos eventos causativos: el enriquecimiento de un sujeto que causa un detrimento a otro, y el enriquecimiento que causa injuria [iniuria] a otro ${ }^{14}$.

El enriquecimiento que causa un detrimento o empobrecimiento correlativo corresponde a la hipótesis clásica del enriquecimiento injustificado, que puede verse expresado en el supuesto del pago de lo no debido: el sujeto que paga erróneamente lo que no debe se empobrece a expensas de quien recibe el pago. Hay un desplazamiento patrimonial que da origen a la obligación de restituir. En este caso, no se requiere un acto ilícito de parte de quien recibe el pago. El hecho generador de la obligación de restituir surge exclusivamente a partir del desplazamiento patrimonial. En el segundo evento, en cambio, se trata de un acto ilícito o contrario a derecho que genera ganancias a su autor. A diferencia de la primera hipótesis, aquí el demandante debe probar la comisión de una conducta ilícita, que puede dar lugar a una acción indemnizatoria y/o una acción restitutoria. Ambas acciones se relacionan y surgen a partir del mismo hecho, pero son conceptualmente separables. La acción indemnizatoria de responsabilidad civil requiere la existencia y prueba de daño para la víctima, daño que constituirá la medida de la indemnización, mientras que la acción restitutoria no requiere la existencia de daño, sino de un enriquecimiento o ganancia para el sujeto demandado, ganancia que constituirá la medida del remedio.

Actualmente, esta segunda hipótesis restitutoria se conoce en el common law con el nombre genérico de restitución por ilícitos (restitution for wrongs). Respecto a la designación del remedio correspondiente a este tipo de restitución, no hay acuerdo en la doctrina. Se han planteado los nombres de disgorgement damages, restitutionary damages, account for profits, licence fee damages, o gain-based damages. Al igual que en el caso de la doctrina alemana, los supuestos paradigmáticos de esta hipótesis se encuentran asociados a ilícitos vinculados al derecho de propiedad. El caso más conocido es EDWARDS V. LEE'S ADMINISTRA$T O R$ (1936) de Estados Unidos, en el cual el demandado descubre una caverna de roca de cristal en el subsuelo de su propiedad, que explota como atracción turística. Sin embargo, una sección de la caverna pertenecía al subsuelo de una propiedad colindante, cuyo dueño era el demandante. La Corte de Apelaciones de Kentucky otorga a los demandantes la restitución de un tercio de las ganancias obtenidas por el demandado mediante la explotación turística de las cavernas, proporción que se calculó basándose en la porción de terreno que correspondía al demandante de la caverna completa. El remedio otorgado por la Corte en este caso es claramente restitutorio y no indemnizatorio, puesto que el demandante no sufrió daño por la utilización del subsuelo de su propiedad. El acceso a las cavernas se encon-

\footnotetext{
11 Virgo (2015) p. 3.

12 Birks (2005) p. 4.

13 Dig. 50,17,206.

14 Birks (1999) pp. 172-173.
} 
traba en el terreno de propiedad del demandado, por lo cual ni siquiera sería posible plantear la posibilidad de una eventual indemnización por lucro cesante. Por otra parte, se trata de un caso de restitución por ilícitos, puesto que aquí no hay un desplazamiento patrimonial, sino más bien una atribución patrimonial impropia por parte del demandado, a partir de la comisión de un ilícito civil como es la invasión de propiedad ajena sin autorización de su dueño (trespass), en la cual la medida de la restitución es determinada sobre la base de las ganancias obtenidas por el demandado como consecuencia de la comisión del ilícito civil.

El presente trabajo abordará este problema bajo el nombre general de restitución de ganancias ilícitas, a partir de lo que en common law se conoce con el nombre de restitución por ilícitos, constituyendo una categoría conceptual más amplia que permite cubrir lo que se conoce en derecho alemán como acción de enriquecimiento por intromisión en derecho ajeno. Se trata de la acción restitutoria sobre aquellas ganancias que han sido obtenidas ilícitamente, ya sea provenientes de una invasión o utilización de propiedad ajena, del incumplimiento de obligaciones fiduciarias, o de un ilícito civil extracontractual. De esta manera, mediante el empleo de la figura conceptual de la restitución de ganancias ilícitas, se pretende dar cuenta no solo de los casos de intromisión en derecho ajeno (típicamente intromisiones en derechos absolutos como el derecho de propiedad del demandante), sino también de otros casos en los cuales el demandado comete un acto ilícito y obtiene ganancias como consecuencia de ello. Desde luego, estos casos pueden dar lugar también a una acción indemnizatoria de responsabilidad civil, con lo cual se producirá un concurso de acciones. En este sentido, serán particularmente interesantes aquellos casos en los cuales la víctima no ha sufrido propiamente un daño producto del acto ilícito o el daño es inferior al beneficio obtenido por el infractor. En estos supuestos, la acción restitutoria resultará ser una alternativa más atractiva que la vía indemnizatoria. A partir del amplio desarrollo doctrinario en los sistemas del common law y el derecho alemán, resulta entonces de interés plantear una discusión en torno a estas hipótesis en el contexto del derecho privado chileno, contexto en el cual la discusión no ha sido abordada con suficiente detenimiento. El punto de partida para dicha discusión es identificar los supuestos en los cuales el legislador ha contemplado expresamente este remedio.

\section{LOS SUPUESTOS DE RESTITUCIÓN DE GANANCIAS EN EL DERECHO COMPARADO}

En general, este tipo de remedios se decretan en casos de infracción a derechos absolutos que conceden a su titular el goce exclusivo del derecho. El reciente Restatement (Third) of Restitution and Unjust Enrichment estadounidense de 2011 (en adelante Restatements $)^{15}$ nos puede contribuir a elaborar un catálogo de estas hipótesis:

i. Incumplimiento contractual (\$ 39).

ii. Interferencias en intereses protegidos sobre la propiedad corporal, mediante los ilícitos de trespass o conversion ( $\$ 40$ ).

iii. Apropiaciones indebidas de activos financieros $(\$ 41)$.

15 American LaW Institute. 
iv. Infracciones de derechos protegidos jurídicamente en una idea, expresión, información, imagen o designación (\$ 42 ).

v. Incumplimientos de algún deber fiduciario o la violación de un deber equivalente impuesto por alguna relación de confianza $(\$ 43)$.

A partir de estos supuestos, pueden identificarse dos grandes problemas que han surgido persistentemente en la doctrina alemana y anglosajona. El primero consiste en determinar cuál es el fundamento y naturaleza de la acción. El segundo consiste en resolver si la acción restitutoria es compatible con la indemnizatoria.

\section{LOS FUNDAMENTOS Y NATURALEZA JURÍDICA DE LA ACCIÓN}

Resulta indudable que la generación de cualquier ganancia, incluso de origen ilícito, no puede dar lugar a una acción restitutoria. La existencia de la acción debe ser equilibrada en razón de la seguridad jurídica que sugiere el hecho de que el enriquecimiento permanezca en el patrimonio en el cual se encuentra ${ }^{16}$. Debe existir, por lo tanto, una razón que justifique la necesidad de desplazar el enriquecimiento del demandado al patrimonio del demandante. La doctrina alemana, seguida por la doctrina española, ha formulado dos grandes teorías: la teoría de la antijuridicidad y la teoría de la atribución ${ }^{17}$. La primera de ellas plantea que el enriquecimiento se califica como injustificado por la antijuridicidad de la intromisión, teoría que ha sido rechazada ampliamente por la doctrina alemana mayoritaria ${ }^{18}$. Es la teoría de la atribución planteada por Wilburg y desarrollada por von Caemmerer, en tanto, la que se ha impuesto definitivamente ${ }^{19}$. Esta concepción, como ya se mencionó anteriormente, surge a partir de la exclusividad que el derecho de propiedad le otorga al dueño de la cosa. Esta infracción al derecho del propietario es lo que permite justificar la restitución de ganancias incluso en aquellos casos en que el titular del derecho no tenía intención alguna de emplear la cosa que fue indebidamente utilizada por el demandado. Para muchos, en consecuencia, la restitución de ganancias surge como el remedio más idóneo para reparar la infracción al derecho de propiedad; el demandado debe devolver al dueño las ganancias obtenidas ilícitamente "como si nada hubiese ocurrido", restituyendo a su dueño lo que le pertenecía ${ }^{20}$.

En este ámbito, pareciera ser claro el fundamento de la exclusividad en el goce para justificar el remedio de la restitución de ganancias, especialmente tratándose de derechos absolutos como el de propiedad sobre cosas corporales, o en la propiedad industrial e intelectual. Sin embargo, las dudas surgen a partir de la determinación en concreto del remedio restitutorio. La doctrina alemana en su mayoría sostiene que la función de la Eingriffskondiktion es de reintegración o reconstrucción económica, lo que significa que el remedio restitutorio debe perseguir llegar al mismo resultado al que se habría llegado de haberse

\footnotetext{
16 BASOZÁbal (1998) p. 53.

17 Dannemann (2009) p. 94; Díez Picazo (2011) pp. 174-177.

18 Basozábal (1998) p. 56; Dannemann (2009) p. 94.

19 Zimmermann y du Plessis (1994) p. 27; Krebs (2006) p. 383.

20 Ripstein (2007) pp. 1991-1995.
} 
seguido el cauce jurídico adecuado, esto es, habiéndose solicitado la autorización previa al titular del derecho ${ }^{21}$. Ello excluye la necesidad de demostrar la existencia de un daño para el demandante, y de imputación subjetiva por parte del demandado. Excluye, de tal manera, consideraciones punitivas. Bajo esta concepción, el remedio no exige la restitución de todas las ganancias obtenidas por el demandado como consecuencia de su infracción, sino solo la restitución del monto de dinero que se evitó pagar el demandado para obtener autorización por parte del titular del derecho a modo de regalía. El problema lo constituyen las conductas intencionales. Si al sujeto le es indiferente entre utilizar una cosa ajena sin autorización y pagar después, o pedir autorización pagando antes, entonces el sujeto no tiene incentivo alguno para negociar en forma previa y seguir el cauce jurídico adecuado.

En el common law, la doctrina y jurisprudencia distingue entre dos tipos de remedios de restitución de ganancias: los llamados licence fee damages y los disgorgement damages. Los primeros corresponden al remedio restitutorio planteado por la doctrina alemana: exigen la restitución del precio que el demandado habría pagado para obtener el consentimiento del titular del derecho. El caso más relevante de este tipo de remedios lo constituye el caso inglés Wrotham Park Estates Ltd. V. Parkside Homes Ltd. (1974). En este caso, el demandado construyó un conjunto de casas en un terreno colindante con el de los demandantes, violando una cláusula contractual, según la cual se requería la aprobación de planos por parte de los demandantes para edificar en dicho terreno. Se determinó que el mecanismo para calcular el monto a pagar por los demandados debe ser equivalente a la "suma de dinero que los demandantes habrían razonablemente exigido a Parkside como quid pro quo para relajar la aplicación de la cláusula" 22 . Lo interesante es que el juez para determinar el monto del remedio toma en cuenta las utilidades efectivamente obtenidas por el demandado con el desarrollo inmobiliario, y determinó que un 5\% de dichas utilidades habrían sido un monto razonable que el demandante podría haber exigido para relajar la cláusula del contrato. Algunos autores incluso denominan a este tipo de remedios como Wrotham Park damages, y se ha planteado que serían más convenientes que el simple pago de un monto de regalía (royalty), puesto que por una parte protegen el derecho del demandante y, por la otra, impiden que el demandado bloquee o ejerza un monopolio sobre la utilización de los recursos. Wrotham Park permite conciliar estos dos intereses. Si bien existe alguna discusión en torno a la naturaleza jurídica de estos remedios, la gran mayoría de la doctrina sostiene que se trata de un remedio restitutorio y no compensatorio ${ }^{23}$.

Sin embargo, se ha planteado un segundo tipo de remedios para abordar los casos de infracciones intencionales o dolosas. Se trata de los disgorgement damages, generalmente reservados para casos de ilícitos dolosos, tal como se señala en $\$ 40$ comentario b de los Restatements: "el autor de un ilícito consciente deberá devolver las ganancias de su interferencia no autorizada con la propiedad de otro; mientras que la responsabilidad restitutoria de un demandado sin culpa no excederá el valor de lo obtenido en la transacción por la cual se

21 Dannemann (2009) p. 95; Krebs (2006) p. 387.

22 Wrotham Park Estates Ltd. v. Parkside Homes Ltd. (1974) p. 815.

23 Por ejemplo, BARKer (2014) se inclina por atribuirle una naturaleza indemnizatoria; Burrows (2007) pp. 635-638 y Edelman (2002) pp. 99-102 sostienen que el remedio es restitutorio. 
atribuye responsabilidad". Aquí el demandado debe entregar todas las ganancias obtenidas como consecuencia de la conducta ilícita, y en general se establece como requisito la imputación subjetiva del demandado a título de dolo.

Por lo tanto, las dudas que surgen en torno a la naturaleza jurídica del remedio persisten en el derecho comparado objeto de este análisis. ¿Se trata de un remedio de carácter exclusivamente restitutorio que prescinde de criterios de imputación subjetiva, o tiene un carácter punitivo que requiere la existencia de dolo como requisito de operatividad? Esta interrogante que se plantea en el derecho comparado se encuentra, como se verá más adelante, latente en los supuestos tipificados por el derecho chileno.

\section{LA COMPATIBILIDAD DE LA ACCIÓN RESTITUTORIA CON LA ACCIÓN INDEMNIZATORIA}

Si la víctima del ilícito no sufre daño como consecuencia del ilícito, solo habrá lugar a una acción restitutoria y por consiguiente ello no dará lugar a concurso de acciones. Pero si la víctima sufre un daño es perfectamente factible, como ya se advirtió, concebir la posibilidad de un concurso de acciones indemnizatoria y restitutoria. La jurisprudencia y doctrina comparadas sostienen en principio que el demandante debiera tener libertad para elegir la acción indemnizatoria o restitutoria, por lo cual no habría razón alguna para sostener que la acción restitutoria tendría un carácter subsidiario. Sin embargo, la interposición conjunta o acumulación de ambas acciones resulta más discutible. Así, por ejemplo, Basozábal sostiene la compatibilidad de las acciones, siempre y cuando no exista una coincidencia material entre las dos pretensiones ${ }^{24}$. En el derecho inglés, por el contrario, se le permite al demandante elegir libremente entre la acción indemnizatoria o restitutoria (probablemente la que más convenga a sus intereses), pero no se permite la interposición conjunta de ambas $^{25}$. Así también se contempla en el $\$ 42$ comentario de los Restatements.

Entre nosotros, Barros defiende una solución similar a la del derecho inglés: "el concurso de acciones indemnizatoria y restitutoria es alternativo, esto es, se puede ejercer una u otra, pero no pueden ser acumuladas, porque actuar sobre los beneficios supone, en cierto sentido, condonar el ilícito" ${ }^{26}$. Sin embargo, agrega Barros que la excepción la constituyen los casos en los cuales un mismo hecho tiene distintas calificaciones por afectar bienes jurídicos distintos, y posteriormente también señala los casos en los cuales el ilícito extracontractual requiere dolo (refiriéndose a las hipótesis de los artículos 1458 y 2316 del Código Civil), donde sostiene que es posible la concurrencia de la acción indemnizatoria con la de restitución de beneficios ${ }^{27}$.

\footnotetext{
24 BASOZÁBAL (1998) pp. 106-111.

25 Burrows (2007) p. 627.

26 Barros (2009) p. 66.

27 Barros (2009) pp. 76-77.
} 


\section{LA RECEPCIÓN Y DISCUSIÓN DE LA ACCIÓN EN EL DERECHO PRIVADO CHILENO}

Una vez delineadas las principales características de la restitución de ganancias provenientes del derecho comparado, nos haremos cargo en esta sección de su recepción en el derecho privado chileno. El CC carece de una norma general que consagre la restitución de ganancias ilícitas en general. Sin embargo, al igual que en el caso del principio general del enriquecimiento injustificado, es posible identificar hipótesis típicas de restitución de ganancias ilícitas, tanto dentro del CC como en leyes especiales ${ }^{28}$. Estos supuestos pueden clasificarse en cuatro grandes categorías:

1) Interferencias al derecho de propiedad sobre cosas corporales en el CC.

2) La acción de provecho por dolo ajeno (artículos 1458 y 2316 del CC).

3) Restitución de ganancias asociadas a infracciones al derecho de propiedad sobre cosas incorporales (propiedad industrial e intelectual).

4) Infracciones a deberes fiduciarios de directores de sociedades anónimas y el decomiso por uso de información privilegiada.

\section{LAS INTERFERENCIAS AL DERECHO DE PROPIEDAD SOBRE COSAS CORPORALES}

En la regulación del derecho de dominio abordado por el CC, podemos identificar diversas hipótesis de restitución de ganancias no tratadas sistemáticamente. Díez Picazo, en relación con el derecho español, plantea una distinción entre dos grupos de casos de intromisiones en el derecho de propiedad ajena: (i) la utilización de bienes ajenos y (ii) el ejercicio indebido del ius disponendi ${ }^{29}$. La utilización de bienes ajenos comprende la utilización de cosas ajenas, el ius fruendi u obtención de frutos naturales o civiles que la cosa ajena hubiere producido, y la utilización del bien para la creación o construcción de una cosa distinta $^{30}$. Por su parte, el segundo grupo de supuestos comprende aquellos casos en los cuales la facultad de disposición sobre un bien es ejercitada por un sujeto que carecía de la facultad para disponer de la cosa, y un tercero adquiere la posesión de ella por encontrarse de buena fe, amparándose en la protección de la apariencia ${ }^{31}$. A continuación, se describen los casos que pueden identificarse dentro del CC.

\section{a. La acción del dueño del terreno en contra de quien descubre un tesoro (art. 626)}

El artículo 626 establece que el tesoro encontrado en terreno ajeno se dividirá en partes iguales entre el dueño del terreno y la persona que hizo el descubrimiento, pero solo en caso que el descubrimiento haya sido fortuito o que quien hizo el descubrimiento haya contado con el permiso del dueño. En esta hipótesis, la ganancia determinada por el tesoro

28 Un catálogo de estas acciones en el derecho chileno puede encontrarse en Momberg (2015), aunque comprende también hipótesis propias del derecho público en las que se establecen multas calculadas sobre la base de las ganancias obtenidas por el infractor.

29 Díez Picazo (2011) pp. 178-187.

30 Díez Picazo (2011) p. 178. Más sobre esto en el reciente trabajo de BeCH (2018).

31 Díez Picazo (2011) p. 186. 
se restituye en su totalidad al titular del derecho de propiedad, a menos que el descubrimiento haya sido fortuito o que quien realiza el descubrimiento haya solicitado la autorización previa. La acción que el artículo 626 le otorga al dueño del terreno donde se realiza el descubrimiento no puede tener un carácter indemnizatorio, puesto que se trata precisamente de un supuesto de creación de riqueza, que no genera perjuicio alguno para el dueño. La norma establece una solución al conflicto entre, por una parte, la pretensión legítima del dueño del terreno de apropiarse del descubrimiento, y por la otra, la pretensión (en principio, también legítima) de quien realiza el descubrimiento de apropiarse de la cosa.

Debe tenerse presente que se trata de objetos que "han estado largo tiempo sepultados o escondidos sin que haya memoria ni indicio de su dueño" (art. 625). Si las cosas están sepultadas o escondidas, ello supone que quien realiza el descubrimiento invirtió su tiempo y trabajo en la búsqueda del tesoro. La norma se inclina claramente a favor del dueño, y en razón de la exclusividad del dominio, puede demandar a quien realiza el descubrimiento la restitución de todo el tesoro. La ilicitud de la conducta se determina por la invasión del derecho de propiedad del demandante, dado que la acción supone que quien realiza el descubrimiento no contaba con la autorización del dueño para la búsqueda del tesoro, o fue fortuita. Se trata entonces de una acción restitutoria de ganancias de utilización de bienes ajenos, en la cual el demandado debe devolver todas las ganancias obtenidas como consecuencia de la vulneración del derecho de propiedad del demandante, sin requerir imputación subjetiva del descubridor. No obstante, se establece que si el descubrimiento es fortuito, la división será en partes iguales. Misma solución adoptada por el legislador en caso de que la búsqueda hubiese contado con la autorización del dueño del terreno.

\section{b. $\quad$ La accesión de cosas muebles a inmuebles (arts. 668 y 669)}

Resulta bastante claro que las reglas de accesión de los artículos 668 y 669 del CC aplican criterios asociados al enriquecimiento injustificado ${ }^{32}$. En el artículo 668, el dueño que edifica en su terreno con materiales ajenos debe pagar al dueño de los materiales su “justo precio, u otro tanto de la misma naturaleza, calidad y aptitud”, debido a que se hará dueño de los materiales ajenos por incorporarse a su terreno. De tal manera que nos encontramos con una hipótesis clara de restitución de ganancias obtenidas mediante la comisión de un acto ilícito. La ilicitud de la conducta por parte del dueño del terreno consiste en la utilización de materiales ajenos sin haber solicitado la autorización previa correspondiente. Tan clara resulta la conducta ilícita del dueño del terreno que el inciso segundo de la norma establece una hipótesis tipificada de responsabilidad extracontractual en caso de haber actuado con culpa (sin una "justa causa de error"), y responsabilidad penal para el caso de que haya actuado con dolo ${ }^{33}$. Pero respecto a la acción restitutoria establecida en el inciso

\footnotetext{
32 Véase, por ejemplo, Peñailillo (2006) p. 208. Así también lo ha entendido la Corte Suprema en CISTERNAS CON LOREN (2012) cons. $7^{\circ}$.

33 Por ello es que, a mi juicio, se equivoca la Corte Suprema en la sentencia recién citada cuando sostiene que para que opere la acción restitutoria "resulta necesario que no exista entre las partes una relación patrimonial, ya sea derivada de un contrato, de un hecho ilícito o de la mera ley” (CISTERNAS CON LOREN (2012) cons. $7^{\circ}$ ). La acción restitutoria es perfectamente compatible con la existencia de un hecho ilícito, tal como el mismo texto del art. 668 inc. $2^{\circ}$ lo demuestra.
} 
primero del artículo 668, no se requiere imputación subjetiva. Al demandante le basta probar la titularidad de dominio sobre los materiales utilizados y que el demandado carecía de autorización para la utilización de los materiales, esto es, ausencia de un contrato que legitime la utilización del bien (como una compraventa o permuta).

La técnica entonces del artículo 668 inciso primero corresponde a la solución adoptada por la doctrina alemana de la atribución o pago de regalías (royalty fees): el infractor debe pagar a la víctima del ilícito una compensación correspondiente a la suma que debería haber pagado para obtener la autorización del dueño de los materiales. Ello explica la referencia al "precio justo" de la disposición jurídica, en la medida que ello permite poner a la víctima en la misma posición en que se encontraría de haber el dueño del terreno contratado con ella desde un comienzo. Así las cosas, se presentan los aspectos característicos de la acción restitutoria de ganancias ilícitas: no se requiere imputación subjetiva, el demandado ha cometido un acto ilícito, y el remedio consiste en la restitución de las ganancias obtenidas por el infractor. Lo anterior demuestra que resulte inadecuado comprender la acción del artículo 668 como una indemnización por lucro cesante, toda vez que se impone una venta forzada para el dueño de los materiales que no necesariamente habría estado dispuesto a aceptar. En este sentido, el remedio es restitutorio porque solo atiende a las ganancias obtenidas por el infractor, que consisten en haberse ahorrado el gasto de negociar con la víctima.

El artículo 669 regula la situación inversa, esto es, la del sujeto que construye en terreno ajeno sin autorización del dueño. Aquí nuevamente el enriquecimiento injustificado permite corregir el enriquecimiento que se presenta esta vez para el dueño del terreno, el cual mediante el modo de adquirir accesión se beneficiará con la construcción no consentida. Aquí se distinguen dos situaciones distintas. Por una parte, el inciso primero regula el caso de quien construye en terreno ajeno sin conocimiento del dueño, en cuyo caso la norma le otorga una opción al dueño: puede "hacer suyo el edificio" pagando las indemnizaciones correspondientes a las prestaciones mutuas en la acción reivindicatoria, o puede optar por demandar al constructor el pago del justo precio del terreno con los intereses legales por todo el tiempo que lo haya tenido en su poder. Por otra parte, el inciso segundo regula el caso de quien construye en terreno ajeno "a ciencia y paciencia del dueño", caso en el cual el dueño debe pagar el valor total del edificio construido.

La redacción del inciso primero de la disposición ha dado lugar a una importante dificultad interpretativa. Dada la expresión utilizada por el legislador de "hacer suyo el edificio", Ramos Pazos ha planteado que mientras el dueño no ejerza la opción que le otorga la norma, el constructor es el dueño de la cosa bajo la condición resolutoria de que el dueño del terreno ejerza la primera opción pagando las indemnizaciones correspondientes, momento en el cual el dueño del terreno adquiere por accesión el dominio de la cosa ${ }^{34}$. La interpretación ha sido acogida en general por la jurisprudencia ${ }^{35}$. En contra, Atria sostiene que esta interpretación es "insostenible", debido a la inconsistencia con la solución del Código en el artículo 668, en la cual se trataría de manera menos favorable al dueño que cons-

34 Ramos Pazos (1985) p. 145.

35 ROJAS CON DIAZ (2016). 
truye con materiales ajenos. Por ello, propone que "hacer suyo el edificio" y "recobrarlo" aquí significa en realidad darle la posibilidad al dueño de recuperar el uso y goce de la cosa, que se encuentra en manos del constructor ${ }^{36}$.

Sin pretender agotar el debate sobre este punto, podemos aquí partir de la base de que el constructor incurre también en una conducta ilícita, en la medida que construye en un terreno sin autorización previa de su dueño. En tal evento, si el dueño del terreno opta por exigirle al constructor que le pague el "justo precio del terreno" se tratará de una acción restitutoria de ganancias ilícitas, en la medida que el constructor se apropia de un terreno sin obtener autorización de su dueño y el remedio restitutorio opera bajo la lógica del "justo precio”, similar a la solución adoptada por el artículo 668. Por otra parte, si el dueño del terreno opta por la primera opción de "hacer suyo el edificio" (o recuperar el uso y goce del terreno), quien deberá restituir ganancias será el propio dueño del terreno, de acuerdo a las normas sobre prestaciones mutuas para el caso del poseedor vencido.

En esta hipótesis es el propio demandante (el dueño del terreno) quien debe restituir las ganancias al constructor como condición para "hacerse dueño" del edificio. Desde luego que la interpretación de Atria permite entender la razón por la cual tendría sentido para el dueño ejercer la acción: para recuperar el uso y goce del inmueble. Como condición para que ello ocurra, el CC establece que el dueño deberá pagar las indemnizaciones que correspondan según las reglas sobre prestaciones mutuas. Bajo el ejercicio de esta opción, a mi juicio, no hay un supuesto de restitución de ganancias ilícitas en el sentido que hemos aquí adoptado, sino de enriquecimiento injustificado con un desplazamiento patrimonial. La situación se asemeja a la de quien paga lo que no debe: un sujeto (el dueño del terreno) se enriquece a expensas de otro (el constructor) en virtud del principio superficies solo cedit, por lo cual la acción restitutoria corrige el desplazamiento patrimonial que se produce entre quien construye y el dueño del terreno.

Lo anterior resulta también aplicable a la hipótesis contemplada en el inciso segundo del artículo 669. Al igual que en el caso anterior, es el dueño quien debe restituir los beneficios que le importan la construcción no consentida. La diferencia radica exclusivamente en que el tratamiento al dueño en el caso del inciso segundo del artículo 669 es menos privilegiado, en la medida que deberá pagarle al constructor el valor total del edificio. Si bien la doctrina tradicional entiende que en este caso opera la tradición como modo de adquirir el dominio, en virtud de que el inciso segundo supondría consentimiento por parte del dueño para la construcción del edificio ${ }^{37}$, se ha sostenido que la acción debe comprenderse como una hipótesis de enriquecimiento injustificado ${ }^{38}$. El punto radica en que precisamente el constructor no tiene una acción de restitución de ganancias en contra del dueño del terreno; solo podrá exigir el pago de la compensación en la medida en que el dueño lo demande para recuperar el uso y goce del edificio ${ }^{39}$.

\footnotetext{
36 Atria (2004) p. 27. En el mismo sentido GonZÁlez (2017) p. 245.

37 Claro Solar (1932) pp. 230 y ss.

38 GonZÁlez (2017) p. 249.

39 Esto se detecta adecuadamente en GonZÁlez (2017) p. 251 nota 111. También la Corte Suprema: FROHLICH CON DIETZ (2002), sentencia de reemplazo, cons. $7^{\circ}$.
} 
De manera tal que, al igual que en el caso de la primera opción que le otorga al dueño el artículo 669 inciso $1^{\circ}$, en el caso del inciso $2^{\circ}$ no hay propiamente una acción de restitución de ganancias ilícitas, sino más bien una acción de enriquecimiento injustificado. En suma, la acción del artículo 668 del constructor contra el dueño que construye en terreno propio con materiales ajenos, y la acción del dueño del terreno en contra de quien construye en terreno ajeno sin conocimiento del dueño para que pague el justo precio del terreno con los intereses legales, constituyen hipótesis tipificadas de restitución de ganancias ilícitas en el sentido que aquí se ha venido utilizado.

\section{c. Las obligaciones restitutorias del poseedor vencido en acción reivindicatoria (arts. 906 y 907)}

El artículo 906 del CC establece en primer término que el poseedor vencido de mala fe es responsable de los deterioros que por su hecho o culpa ha sufrido la cosa. Luego, el inciso $2^{\circ}$ de la norma establece que "[e]l poseedor de buena fe, mientras permanece en ella, no es responsable de estos deterioros, sino en cuanto se hubiere aprovechado de ellos; por ejemplo, destruyendo un bosque o arbolado, y vendiendo la madera o la leña, o empleándola en beneficio suyo" [énfasis añadido]. De manera tal que regla general establecida por la norma es que el poseedor de buena fe no es responsable de los deterioros que por su hecho o culpa ha sufrido la cosa reivindicada. Esta regla se justifica en razón de que el poseedor, al encontrarse de buena fe, goza de la presunción de dominio, por lo cual puede comportarse como dueño y sufrir el deterioro de la cosa ${ }^{40}$.

La excepción la constituye el caso en el cual el poseedor de buena fe se hubiere aprovechado del deterioro de la cosa. La norma no se refiere a los frutos que produce la cosa, que quedan regulados en el artículo 907, sino a los beneficios que el poseedor hubiere obtenido como consecuencia del deterioro de la cosa. Tal como lo señala Javier Barrientos, la referencia a en cuanto se hubiere aprovechado de ellos debe entenderse de la misma manera que las normas del CC que se refieren a hacerse más rico [si locupletior factus est], como el caso del invasor de buena fe de herencia ajena (art. 1267) o la acción de nulidad dirigida en contra del incapaz (art. 1688) ${ }^{41}$. Así las cosas, el dueño reivindicante tendrá acción en contra del poseedor vencido de buena fe por los deterioros que por su hecho o culpa ha sufrido la cosa en la medida en que haya obtenido un provecho o beneficio como consecuencia del deterioro de la cosa. De manera tal que se trata de una acción claramente restitutoria, ya que, si bien se trata de un deterioro sufrido por la cosa, la medida del remedio se determina por los beneficios obtenidos por el demandado, y dichos beneficios fueron obtenidos como consecuencia de la intromisión en el derecho de propiedad del dueño reivindicante. Nos encontramos aquí entonces con una nueva hipótesis tipificada de restitución de ganancias ilícitas, en la cual es irrelevante que el sujeto se haya encontrado de buena fe; debe, igualmente, restituir las ganancias obtenidas a partir de su interferencia con el derecho de propiedad del verdadero dueño.

40 Barrientos (2016) pp. 1052-1053.

41 Barrientos (2017) pp. 76-87. 
Por otra parte, el artículo 907 del CC obliga al poseedor vencido de mala fe a restituir los frutos naturales y civiles de la cosa reivindicada. La regla permite al dueño de la cosa solicitar la restitución de las ganancias obtenidas por el poseedor vencido sin requerir daño, por el solo hecho de ser el verdadero dueño y el poseedor encontrarse de mala fe. Por ende, se trata también de una hipótesis de restitución de ganancias o condictio por intromisión. En este caso, la acción exige como requisito de procedencia que el poseedor se encuentre de mala fe, por lo cual constituye a una excepción por cuanto las acciones restitutorias de ganancias por regla general no requieren imputación subjetiva del demandado.

La regla del artículo 907 resulta interesante además por obligar a restituir al poseedor de mala fe no solo los frutos efectivamente obtenidos como consecuencia del uso y goce de la cosa, "sino los que el dueño hubiera podido percibir con mediana inteligencia y actividad, teniendo la cosa en su poder”. Establece entonces un estándar muy exigente con el poseedor de mala fe, en el cual podría ser obligado a restituir más de lo que efectivamente haya percibido en poder de la cosa. Desde el punto de vista restitutorio (y no sancionatorio o preventivo), la norma puede ser criticable, en tanto se obliga al demandado a restituir más que los beneficios o ganancias efectivamente percibidos. El remedio podría ser superior al enriquecimiento del demandado.

\section{d. La acción reivindicatoria en contra de quien enajenó la cosa (art. 898)}

Por último, cabe mencionar el caso de la acción reivindicatoria en contra de quien enajenó la cosa, por la restitución del valor que haya recibido por ella, contemplada en el artículo 898. Como explica Birks, las acciones propietarias generalmente no constituyen acciones restitutorias, en la medida que reivindican el derecho de dominio preexistente del titular del derecho ${ }^{42}$. El derecho de la restitución, en cambio, genera una nueva obligación de restituir. En el caso del artículo 898, la obligación en naturaleza de la acción reivindicatoria ya no es posible por haberse enajenado la cosa. Nace, como consecuencia de ello, una nueva obligación restitutoria de ganancias ${ }^{43}$. En este caso, la ganancia equivale al monto que quien la enajenó hubiese efectivamente recibido. Señala además la norma que en caso de que se haya enajenado a sabiendas de que la cosa era ajena, el demandado estará obligado a indemnizar todo perjuicio. Ello podría constituir un caso más de acumulación de la acción restitutoria con la indemnizatoria, condicionando esta última a la existencia de dolo, al igual que en el caso del artículo 668 ya mencionado ${ }^{44}$. Con todo, también es posible sostener que se trata de

\footnotetext{
42 Birks (1985) pp. 13-16.

43 En el mismo sentido se pronuncia José Pablo Vergara, en Vergara (1987) p. 7. Véase también Barros (2009) p. 26 nota 20.

44 Aunque es posible argumentar que la norma no admite acumular ambos remedios, por cuanto la historia de la ley parece sugerir que la restitución de ganancias sería aplicable solo en el caso de quien poseía de buena fe, mientras que, si se poseía de mala fe, solo sería procedente la indemnización de perjuicios. Particularmente relevante sería la expresión del artículo 1045 del Proyecto de 1853, el cual indicaba que el reivindicador no tendrá derecho a "ser indemnizado dos veces por un mismo perjuicio". Véase Barrientos (2018) pp. 273-274. Agradezco a un revisor anónimo esta aguda observación.
} 
dos acciones distintas: una restitutoria respecto del poseedor vencido de buena fe, y otra de responsabilidad extracontractual en contra del poseedor de mala $\mathrm{fe}^{45}$.

\section{LA ACCIÓN DE PROVECHO POR DOLO AJENO (ARTS. 1458 y 2316)}

Se ha planteado que las acciones de provecho por dolo ajeno contempladas en los artículos 1458 y 2316 del CC tendrían una naturaleza restitutoria, y por ello debieran también considerarse como casos de restitución de ganancias ${ }^{46}$. Este planteamiento fue acogido recientemente por la Corte Suprema a partir de los casos relacionados con el escándalo financiero de Inverlink ${ }^{47}$. La particularidad que tienen estas normas es que la acción se dirige en contra de un tercero inocente por el provecho que obtuvo, y no en contra de quien cometió el ilícito. Sin embargo, otra parte de la doctrina sostiene que estas acciones tendrían una naturaleza indemnizatoria, atendiendo a la historia de la norma y su tenor literal ${ }^{48}$.

La naturaleza jurídica de estas acciones no solo es importante para determinar las distintas reglas aplicables (plazos de prescripción, requisitos de procedencia, etc.), sino también para determinar la posibilidad de la acumulabilidad entre esta acción contra el tercero inocente y una eventual acción indemnizatoria en contra de quien fraguó el dolo. Cabe señalar que esta acción indemnizatoria es eventual puesto que, como toda acción restitutoria, no se requiere la existencia de daño para que sea procedente. Gran parte de la doctrina sostiene que ambas acciones son distintas y que, por lo tanto, no habría obstáculo alguno para que el demandante interponga la acción restitutoria y, adicionalmente, interponga la respectiva acción indemnizatoria ${ }^{49}$. Barros, por su parte, sostiene que dada la exigencia de algún tipo de intencionalidad en el ilícito (dolo), "es natural entonces que concurra la pretensión indemnizatoria con la de restitución de beneficios" ${ }^{\prime 2}$, argumento que puede ser reforzado con referencia a la acumulabilidad de acciones de los artículos 668 u 898 analizados más arriba. Sin embargo, la concurrencia de ambas acciones puede resultar problemática, en atención a que debiera evitarse que el demandado se vea obligado a efectuar un doble pago al demandante ${ }^{51}$.

\section{La RESTITUCiÓn DE GANANCIAS ASOCIADAS AL DERECHO DE PROPIEDAD SOBRE COSAS INCORPORALES (PROPIEDAD INDUSTRIAL E INTELECTUAL) \\ Un tercer grupo de casos lo constituyen las normas relativas a la protección de la propiedad industrial e intelectual. Por una parte, el artículo 108 de la Ley № 19.039 de}

\footnotetext{
45 Vergara (1987) p. 7.

46 Barros (2006) p. 932; Pino (2016) pp. 256-257; Pizarro (2009) p. 682.

47 Véase especialmente Corfo con ENERGAS S.A. (2013) y Corfo CON I. Municipalidad de La Pintana (2013). También el Tribunal Constitucional parece compartir esta tesis de la Corte Suprema, al resolver una reciente acción de inaplicabilidad de los artículos 1458 y 2316. BAT CON CORFO (2018), cons. $6^{\circ}$.

48 Barrientos (2016) p. 1068; Domínguez (2009) pp. 221-222.

49 Pizarro (2009) p. 682.

50 Barros (2009) pp. 76-77.

51 Pino (2016) pp. 258-264. Véase en el mismo sentido Momberg (2017) p. 431, aplicado a la acción de restitución de ganancias por incumplimiento contractual.
} 
Propiedad Industrial acoge el sistema alemán denominado del "triple cómputo" 52 , estableciendo que la indemnización de perjuicios ocasionados por la infracción al derecho de propiedad industrial puede determinarse conforme a las reglas generales, o de acuerdo a "las utilidades que haya obtenido el infractor como consecuencia de la infracción" (letra b), o la suma equivalente a "el precio que el infractor hubiera debido pagar al titular del derecho por el otorgamiento de una licencia” (letra c). Sin perjuicio de que la norma señale que se trata de un mecanismo para determinar la indemnización de perjuicios, la hipótesis de la letra b) ha sido calificada por la doctrina como restitutoria ${ }^{53}$, y así también lo ha entendido recientemente el Tribunal Constitucional en dos sentencias ${ }^{54}$. En tanto la norma permite al demandante exigir la restitución de todas las ganancias obtenidas por el demandado como consecuencia de la infracción al derecho de propiedad industrial, se trata claramente de un mecanismo restitutorio. En este caso, la posibilidad de acumular la acción restitutoria con la indemnizatoria se encuentra prohibida expresamente, al requerirse que el demandante deba elegir entre alguno de estos tres mecanismos de cálculo de la "indemnización" 55 . La norma además no requiere grado alguno de imputación subjetiva para que sea procedente la restitución de ganancias. El fundamento de la hipótesis se asocia a un fin preventivo, ya que la indemnización compensatoria o el pago de la licencia en muchos casos puede resultar insuficiente ${ }^{56}$. Sorprendentemente, en las dos sentencias recién mencionadas del Tribunal Constitucional, se consideró inaplicable esta forma de cálculo por inconstitucionalidad, debido a que vulneraría el principio de proporcionalidad ${ }^{57}$. No es este el lugar para efectuar un análisis detallado de estas sentencias ${ }^{58}$. Pero después de ello, no queda claro si la norma considerada en abstracto resulta inaplicable a cualquier infracción de propiedad industrial, o si, dadas las circunstancias del caso particular sometido a la jurisdicción de la Corte, la norma fue declarada inaplicable para este caso ${ }^{59}$.

Respecto al método de cálculo contemplado en la letra c) del artículo 108, el asunto es más discutible. Como señala el Tribunal Constitucional al respecto, el deslinde entre el lucro cesante y el enriquecimiento ilícito en la norma "no es claro y nítido" ${ }^{00}$. ¿Se trata de la indemnización compensatoria equivalente al lucro cesante, esto es, lo que el demandante dejó de percibir a título de licencias ${ }^{61}$, o se trata de una restitución del beneficio obtenido

\footnotetext{
52 BASOZÁBAL (1997).

53 Barría (2017) p. 206; Barrientos (2008).

54 Astudillo con Compañia Minera Teck Quebrada Blanca S.A. (2014) y Astudillo con Codelco (2014).

55 Desde esta perspectiva, la norma ha sido criticada: "se ha defendido la idea de que una acción de restitución compatible con la indemnización de perjuicios (...) constituye un instrumento disuasivo más potente y de mayor entidad cuantitativa en la lucha contra las infracciones a la propiedad intelectual que aquellas sometidas a un régimen de incompatibilidad”. BARRía (2017) p. 207.

56 Barría (2017) p. 196.

57 Astudillo con Compaña Minera TeCK Quebrada Blanca S.A. (2014) cons. $37^{\circ}$. La misma conclusión en ASTUDILLO CON CODELCO (2014) cons. 39.

58 Un intento de ello en PINO (2015).

59 Esta última pareciera ser la postura del Tribunal especialmente en ASTUDILLO CON CODELCO (2014).

${ }^{60}$ Astudillo con Compañia Minera Teck Quebrada Blanca S.A. (2014) cons. 29³ Astudillo con Codelco (2014) cons. $30^{\circ}$.

${ }^{61}$ En el derecho español, esta interpretación se plantea en CARRASCO (1987) pp. 1143-1144.
} 
por el demandante, como consecuencia de su infracción? ${ }^{62}$ Desde el punto de vista de este trabajo, la calificación de restitutoria de la hipótesis no resulta problemática. En primer lugar, porque el remedio corresponde precisamente al tipo de remedio contemplado por la doctrina alemana para los casos de intromisión en derecho ajeno ${ }^{63}$. Y en segundo lugar, porque el remedio también corresponde a la técnica empleada por las hipótesis tipificadas en el CC que han sido identificadas aquí como restitución de ganancias, por ejemplo en la referencia al "justo precio" de los artículos 668 y $669^{64}$.

Por otra parte, el artículo $85 \mathrm{E}$ de la Ley $\mathrm{N}^{\circ} 17.336$ de Propiedad Intelectual establece que para "determinar el perjuicio patrimonial el tribunal considerará, entre otros factores, el valor legítimo de venta al detalle de los bienes sobre los cuales recae la infracción. El tribunal podrá, además, condenar al infractor a pagar las ganancias que haya obtenido, que sean atribuibles a la infracción y que no hayan sido consideradas al calcular los perjuicios”. Al igual que en el caso del artículo 108 de la Ley de Propiedad Industrial, la redacción de la norma parece no ser la más adecuada, dando a entender que el tribunal puede condenar al infractor a restituir las ganancias que haya obtenido "para determinar el perjuicio patrimonial”. Esta interpretación literalista de la norma es rechazada por la doctrina, que ha entendido que se trata de una hipótesis claramente restitutoria ${ }^{65}$. Nuevamente nos encontramos ante una hipótesis que establece la posibilidad de restituir ganancias ilícitas. Sin embargo, la redacción de la norma es un tanto distinta de la del artículo 108 de la Ley de Propiedad Industrial, en la medida que en este caso se faculta al tribunal para decretar la restitución de ganancias, y no a la víctima para que opte por ello.

Barría sostiene que este artículo 85 E de la Ley de Propiedad Intelectual está mejor diseñado que el artículo 108, "al integrar dos herramientas disuasorias autónomas en contra de las infracciones a los derechos de autor" ${ }^{\$ 6}$. Bajo esta interpretación, conforme a esta norma la víctima tendría a su disposición la acción indemnizatoria y adicionalmente la acción restitutoria de ganancias. Sin embargo, la redacción del texto no es del todo clara. Se sostiene que el tribunal "podrá" condenar al infractor a pagarle a la víctima las ganancias obtenidas. Surge entonces la pregunta de si el tribunal en virtud de la norma puede actuar de oficio o requiere necesariamente solicitud de parte. A mi juicio, dada la redacción de la norma, el juez podría ordenar la restitución de ganancias incluso sin que ello haya sido solicitado por la víctima, y no debiera incurrir en la causal de ultra petita. Adicionalmente a ello, habría que determinar bajo qué circunstancias los jueces "pueden" decretar esta restitución de ganancias (sea a petición de parte o por iniciativa del propio tribunal). La norma pareciera otorgarle un ámbito de discrecionalidad a los jueces para determinar la procedencia de la restitución. También es importante tener en cuenta la expresión "condenar" utilizada por la norma, que podría sugerir un criterio de intencionalidad o dolo para efectos

\footnotetext{
62 Esta discusión se ha desarrollado en el derecho inglés a partir del ya citado caso WROTHAM PARK ESTATES LTD. V PARKSIDE HOMES LTD. (1973). Véase supra II.2.

63 Véase supra II.2.

${ }^{64}$ Véase supra III.1.b.

65 Barría (2017) p. 201; Corral (2013) p. 336.

66 Barría (2017) p. 207.
} 
de decretar la restitución de ganancias. Ello también podría acarrear un eventual juicio de constitucionalidad, al igual que ocurrió en el caso del artículo 108 letra b).

Por último, en relación con la supuesta acumulabilidad de acciones indemnizatoria y restitutoria que permitiría el artículo $85 \mathrm{E}$, cabe tener presente la limitación que contempla la norma, al señalar que el juez puede ordenar la restitución de las ganancias "que no hayan sido consideradas al calcular los perjuicios”. ¿Qué significa esto? Sin duda que hay compatibilidad formal entre las dos acciones. La pregunta abierta es determinar entonces en qué medida el monto de las ganancias habría sido o no considerado para calcular los perjuicios. La compatibilidad formal entre ambas acciones no significa que no deba tomarse en cuenta al momento de determinar ambos remedios.

\section{LA RESTITUCIÓN DE GANANCIAS POR INFRACCIONES A DEBERES FIDUCIARIOS DE DIRECTORES DE SOCIEDADES ANÓNIMAS Y EL DECOMISO POR USO DE INFORMACIÓN} PRIVILEGIADA

Por último, un cuarto grupo de casos lo constituyen las normas relativas a la responsabilidad de los directores de sociedades anónimas por infracción al deber de lealtad. A este efecto, el artículo $42 \mathrm{~N}^{\circ} 7$ de la Ley $\mathrm{N}^{\circ} 18.046$ de Sociedades Anónimas establece que en el caso de infracciones a los números 5, 6 y 7 de la misma norma "los beneficios percibidos por los infractores ... pertenecerán a la sociedad, la que además deberá ser indemnizada por cualquier otro perjuicio”. Asimismo, el artículo $147 \mathrm{~N}^{\circ} 7$ de la misma ley establece que en el caso de realización de operaciones con partes relacionadas, la sociedad o los accionistas tendrán derecho a demandar "el reembolso en beneficio de la sociedad de una suma equivalente a los beneficios que la operación hubiera reportado a la contraparte relacionada, además de la indemnización de los daños correspondientes”. Por último, el artículo 148 inciso $3^{\circ}$ de la misma ley establece una similar regulación para el caso de un director (e incluso accionista) que se apropie de una oportunidad comercial que pertenece a la sociedad. La doctrina chilena ha reconocido estas hipótesis como "una concreción del principio general de derecho referido a la interdicción del enriquecimiento injusto" ${ }^{37}$. Manuel Bernet, en un interesante artículo vincula esta acción de reembolso precisamente con la restitución de ganancias ilícitas (aunque previo a la reforma establecida por la Ley $\mathrm{N}^{\circ} 20.382$, de 20 de octubre de 2009, lo cual no obsta a sus conclusiones) ${ }^{68}$. En este grupo de casos, la restitución de ganancias adopta el carácter de complementario a la indemnización de perjuicios, por lo que eventualmente podrían demandarse ambos remedios conjuntamente.

Por último, el artículo 172 inciso tercero de la Ley $\mathrm{N}^{\circ} 18.045$ de Mercado de Valores establece una acción restitutoria a favor del Estado en contra de quien haga uso de información privilegiada. Señala la disposición: "Las personas que hayan actuado en contravención a lo establecido en este Título, deberán entregar a beneficio fiscal, cuando no hubiere otro perjudicado, toda utilidad o beneficio pecuniario que hubieren obtenido a través de transacciones de valores del emisor de que se trate”. La Corte de Apelaciones de Santiago, en dos sentencias confirmadas por la Corte Suprema, recientemente calificó esta

\footnotetext{
67 Vidal (2011) p. 179; AlCalde (2013) p. 266.

68 Bernet (2007) p. 145.
} 
acción como restitutoria ${ }^{69}$. La particularidad aquí desde la perspectiva del marco teórico aquí planteado, es que el titular de la acción no es un particular, sino el Fisco. Ello ha dado lugar a algunos para sostener que se trata más bien de una norma de carácter penal o sancionatorio ${ }^{70}$. No es este el lugar para un análisis detallado de esta hipótesis ${ }^{71}$, pero cabe señalar que la técnica empleada por el legislador corresponde a una técnica propia del derecho civil, como es la restitución de ganancias. El hecho que sea el Fisco el titular de la acción no obsta a dicha calificación de la acción. Sin embargo, persisten algunas preguntas interesantes a propósito de esta acción. Por ejemplo, ¡es aplicable el artículo en el caso de que el infractor obtenga ganancias superiores a los montos en que hubiere perjudicado a los afectados? ¿Podría el Estado perseguir el saldo de ganancias en este evento? ¿Qué significa "cuando no hubiere otro perjudicado"? ¿Debe el Fisco demostrar que no existe otro perjudicado para que sea procedente la acción?

\section{LAS INTERROGANTES QUE SUSCITA LA RESTITUCIÓN DE GANANCIAS ILÍCITAS EN EL DERECHO PRIVADO}

Ahora bien, una vez calificados los supuestos de la forma indicada, deben enfrentarse algunos problemas que se presentan en la mayor parte de estas hipótesis de restitución de ganancias, que en gran parte han sido enunciados en la discusión de la sección anterior. Estos problemas pueden sistematizarse del siguiente modo:

\section{LA NATURALEZA SUBSIDIARIA DE LAS ACCIONES RESTITUTORIAS}

En general, la mayoría de los ordenamientos jurídicos continentales (a excepción de Alemania) conciben las acciones restitutorias o actio in rem verso como subsidiarias ${ }^{72}$. Lo cierto es que esta supuesta naturaleza subsidiaria de las acciones de enriquecimiento ha generado diversos problemas. En cierta medida, es necesario algún grado de subsidiariedad de estas acciones, puesto que de lo contrario la acción tendría alcances inabarcables. ¿Debiera tener entonces la acción de restitución de ganancias ilícitas una naturaleza subsidiaria? Esta subsidiariedad en algunas de las hipótesis examinadas no se acoge expresamente, como ocurre en el caso del artículo 668 del CC o el artículo 108 de la Ley de Propiedad Industrial. Sin embargo, en otros casos se plantea la acción con algún grado de subsidiariedad, como en el caso del artículo 898 (solo en la medida que el dueño no disponga de la acción reivindicatoria para recuperar la cosa), el artículo 172 inciso $3^{\circ}$ de la Ley de Mercado de Valores (solo si no hubiere otros perjudicados), y discutiblemente en el caso del artículo $85 \mathrm{E}$ de la Ley de Propiedad Intelectual. Al estudiar estas acciones en el contexto de la restitución de ganancias, se puede determinar específicamente si es posible o no justificar algún grado de subsidiariedad de la acción.

69 Fisco de Chile con Irarrazabal UReta (2016) y Fisco de Chile con EBEN ARESTi (2016).

70 Véase SALAH (2004) p. 211, donde se sostiene que la acción "persigue simplemente un afán sancionatorio más bien ajeno al derecho de la responsabilidad civil".

71 Un intento de ello en Pino (2018) pp. 505-524.

72 Véase arts. 1303-3 del nuevo Código Civil francés y 1795 del nuevo Código Civil y Comercial de Argentina. En derecho español, véase Orozco (2015) pp. 339-344. En doctrina chilena, véase Peñailillo (1996) pp. 24-27. 


\section{LA CONCURRENCIA Y COMPATIBILIDAD CON LA ACCIÓN INDEMNIZATORIA}

Dado que la restitución de ganancias ilícitas surge como consecuencia de la comisión de un ilícito, el sistema jurídico normalmente responderá con una acción indemnizatoria y una acción restitutoria (en ciertos casos, también, con una acción penal). En el supuesto de que exista compatibilidad formal entre ambas acciones, ¿existe alguna relación entre ambas? ¿Puede imputarse lo pagado en razón de una acción indemnizatoria a lo que deba pagarse en razón de una acción de restitución de ganancias? Respecto a este punto, el universo de respuestas es diverso ${ }^{73}$. Algunos supuestos nada dicen (por ejemplo, la acción de provecho por dolo ajeno), otros permiten la acumulabilidad expresamente (por ejemplo, el artículo 668 del CC, y las normas de la Ley de Sociedades Anónimas) y otros la prohíben expresamente (por ejemplo, el artículo 108 de la Ley de Propiedad Industrial que obliga a elegir entre una de ellas al demandante). Resulta interesante aquí destacar la técnica empleada por el artículo 85 E de la Ley de Propiedad Intelectual, así como el artículo 172 inciso $3^{\circ}$ de la Ley de Mercado de Valores, ya que permiten la acumulación de ambas acciones, pero tomando en cuenta lo que deba pagarse en una y otra, lo que evita, a mi juicio, que el demandante obtenga un doble pago.

\section{LA RELEVANCIA DE LA CULPA DE LA VÍCTIMA}

La relevancia de la culpa de la víctima es un aspecto discutido en general respecto de las acciones restitutorias. La codificación reciente de Francia reconoce en la culpa de la víctima un efecto mitigador de la acción restitutoria (art. 1303-2), cuestión que había sido largamente discutida en Francia hasta antes de la reforma ${ }^{74}$. Por otra parte, si bien difícilmente la culpa del demandante podría ser un obstáculo para dar lugar a la acción, el criterio podría ser relevante para determinar el quántum del remedio, desde la perspectiva de la causalidad. ¿Podría entonces asignarse a la culpa de la víctima un efecto mitigador de la acción de restitución de ganancias ilícitas como regla general en Chile? Las hipótesis tipificadas omiten cualquier mención sobre el punto, por lo cual se trata de un problema netamente doctrinario, pero respecto al cual ha habido poca discusión en derecho chileno ${ }^{75}$.

\section{LA IMPUTACIÓN SUBJETIVA DEL DEMANDADO}

La mayoría de las hipótesis restitutorias no requieren de imputación subjetiva del demandado como requisito de procedencia. Ello es particularmente notorio en los casos de intromisión en derechos de propiedad. Sin embargo, en algunos casos de restitución de ganancias el remedio supone algún grado de intencionalidad por parte del demandado. Así, por ejemplo, nos encontramos con el artículo 907 del CC (poseedor de mala fe), o la acción de provecho por dolo ajeno que requiere la concurrencia de dolo por parte de quien fraguó el dolo (si bien no lo requiere para el caso del tercero que está siendo demandado).

\footnotetext{
73 Entre nosotros, véase Barros (2009) pp. 30-31.

74 Descheemaeker (2017) pp. 136-137.

75 Lo que resulta llamativo en el caso de la litigación asociada al escándalo financiero Inverlink y la acción de provecho por dolo ajeno, en el cual habría sido un argumento particularmente convincente para rebajar o incluso denegar el remedio restitutorio. Agradezco al profesor Álvaro Vidal este punto.
} 
Este aspecto resulta particularmente relevante para determinar el fundamento de la acción restitutoria. Si se le asigna una función de carácter preventiva o disuasiva al remedio, puede ser importante establecer como requisito de procedencia del remedio algún grado de intencionalidad por parte del demandado.

\section{LA EXTENSIÓN DEL REMEDIO}

Como se señaló al comienzo de este trabajo, la doctrina alemana de la atribución establecía como remedio la medida del "justo precio", o lo que el demandado debería haber pagado al demandante de haber seguido el cauce jurídico adecuado. Algunas de las hipótesis tipificadas por la legislación chilena se ajustan a esta medida (por ejemplo, los artículos 668 y 669 del CC, el artículo 108 letra c) de la Ley de Propiedad Industrial). Sin embargo, otras hipótesis establecen que deben restituirse todas las ganancias obtenidas como consecuencia de la comisión de un ilícito civil (v.gr., el artículo 907 del CC, el artículo 108 letra b) de la Ley de Propiedad Industrial, hipótesis contempladas en la Ley de Sociedades Anónimas). A primera vista y como regla general, la extensión que debiera tener el remedio debiera vincularse con el problema identificado en el párrafo anterior de la imputación subjetiva del demandado: si el demandado actuó sin dolo, resulta más aconsejable una restitución del "justo precio"; mientras que, si el sujeto actuó de manera intencional, debiera ser más adecuada la restitución de todas las ganancias. Lo anterior sigue el criterio de James Edelman, quien sostiene que la restitución de ganancias es necesaria cuando la sola restitución del justo precio o la acción indemnizatoria resulta insuficiente ${ }^{76}$.

\section{LA CAUSALIDAD}

Finalmente, un aspecto que debe ser analizado en aquellas hipótesis en las que el demandado debe restituir todas las ganancias (y no el “justo precio"), es la causalidad. En las acciones de restitución de ganancias ilícitas el juicio de causalidad debe determinarse en relación con el evento ilícito causativo de la restitución, y su vinculación con los beneficios obtenidos por el demandado. Se trata en muchos casos de una labor ardua, en la medida que en muchos casos no existirá una vinculación directa entre los beneficios obtenidos por el demandado (por ejemplo, como consecuencia de una infracción a un derecho de propiedad industrial) y la comisión del ilícito. Si hay factores ajenos a la infracción (por ejemplo, esfuerzo propio, incorporación de ingredientes o modificación de fórmulas), ellos deben ser descontados del remedio restitutorio por carecer de conexión causal. De no descontarse estos gastos y esfuerzos del demandado, se estaría generando un enriquecimiento injustificado para el demandante al beneficiarse del trabajo o los gastos invertidos por el demandado, en una especie de agencia oficiosa ${ }^{77}$.

\footnotetext{
76 Edelman (2002) p. 83.

77 Véase en el mismo sentido American LaW Institute (2011) \$51 comentario h.
} 


\section{CONCLUSIONES}

El objetivo del presente trabajo ha sido identificar los supuestos en los cuales la legislación chilena ha contemplado expresamente como remedio la restitución de ganancias como consecuencia de la comisión de un ilícito civil. Si bien se trata de una figura proveniente del derecho comparado, desarrollada especialmente en el derecho alemán y anglosajón, se ha demostrado aquí que el derecho positivo chileno reconoce la existencia del remedio tanto dentro del CC como en diversas leyes especiales. Algunos de los supuestos acogidos por el derecho positivo chileno corresponden a hipótesis vinculadas a infracciones al derecho de propiedad, que constituye el ámbito tradicional de estas acciones en el caso de mejoras e intromisiones a derechos de propiedad ajena (en el caso de derechos de propiedad industrial e intelectual). En estos supuestos, el fundamento del remedio parece fundarse en el carácter absoluto del derecho de propiedad y el atributo de exclusividad. El remedio normalmente conduce al pago de un justo precio o regalías, y suele tener un carácter objetivo, al no requerir grado alguno de imputación subjetiva del demandado.

Sin embargo, también se han identificado otros supuestos no necesariamente vinculados al derecho de propiedad, en los cuales en general se obliga al demandado a restituir todas las ganancias obtenidas como consecuencia de su actuar ilícito. Estos supuestos suelen ir acompañados de una exigencia adicional de imputación subjetiva del demandado, generalmente de dolo. Ello permite justificar estos remedios sobre la base de que nadie puede aprovecharse de su propio dolo, y por otra parte con una finalidad preventiva o disuasoria. Estos grupos de casos aparecen relacionados con la existencia de deberes fiduciarios en el ámbito del derecho societario chileno.

Se trata de un remedio que ha sido poco estudiado por la doctrina chilena, no obstante su consagración legal en diversos cuerpos normativos. Si bien el ejercicio realizado por este trabajo podría ser calificado como meramente taxonómico, a mi juicio esta clasificación permite dar cuenta de una serie de problemas comunes a todos estos supuestos restitutorios. La clasificación de estos remedios como restitución de ganancias ilícitas permite abordar de manera más adecuada estos problemas, y en forma sistemática. Por lo demás, la calificación de un supuesto como restitutorio o indemnizatorio no es baladí; ello incide en los requisitos de procedencia, los plazos de prescripción, la relevancia de la culpa de la víctima y la extensión del remedio, entre otros aspectos. Un problema particularmente atingente es el de determinar la compatibilidad (o incompatibilidad) de este remedio con una eventual acción indemnizatoria, aspecto resuelto por el legislador solo en algunos de los supuestos tipificados. Por lo mismo, es importante efectuar la calificación de estos supuestos como restitución de ganancias ilícitas en el derecho privado chileno. Ello, adicionalmente, permite abrir la discusión en torno a la posibilidad de plantear la disponibilidad del remedio de restitución de ganancias ilícitas en supuestos no acogidos expresamente por la legislación chilena, como ocurre por ejemplo en el caso de la restitución de las ganancias obtenidas por el deudor como consecuencia de un incumplimiento contractual, figura reconocida en el derecho anglosajón ${ }^{78}$, y que también ha sido recientemente discutida en Chile $^{79}$.

\footnotetext{
78 Véase American Law Institute (2011) \$ 39; Burrows (2007) pp. 663-677.

79 A favor, Momberg (2017), en contra Prado (2018).
} 


\section{BIBLIOGRAFÍA CITADA}

Abeliuk Manasevich, René (2008): Las obligaciones (Santiago, Editorial Jurídica de Chile, quinta edición).

Alcalde Rodríguez, Enrique (2013): La responsabilidad de los directores de sociedades anónimas (Santiago, Ediciones Universidad Católica de Chile).

American Law Institute, Restatement of the Law (Third) Restitution and Unjust Enrichment (2011): (St Paul, American Law Institute).

Atria Lemaitre, Fernando (2004): "Adquisición de derechos reales", Revista de Derecho de la Universidad Adolfo Ibañez, No 1: pp. 21-56.

Barker, Kit (2014): “'Damages Without Loss': Can Hohfeld Help?”, Oxford Journal of Legal Studies, Vol. 34, No 4: pp. 1-28.

BARRÍA, Rodrigo (2017): "La función preventiva o disuasoria de la responsabilidad civil, a propósito de las Leyes de Propiedad Intelectual y de Propiedad Industrial”, en: del mismo et al. (edits.), Presente y Futuro de la Responsabilidad Civil (Santiago, Thomson Reuters) pp. 177-213.

Barrientos Grandón, Javier (2016): El Código Civil. Su jurisprudencia e historia, Tomo II (Santiago, Thomson Reuters).

Barrientos Grandón, Javier (2017): "Enriquecimiento injustificado y codificación: modelos y decisiones dogmáticas (siglo XIX)”, en Del Olmo García, Pedro y Basozábal ArruÉ, Xabier (edits.), Enriquecimiento injustificado en la encrucijada: Historia, derecho comparado y propuestas de modernización (Navarra, Aranzadi) pp. 49-119.

Barrientos Grandón, Javier (2018): Las condiciones en el Código Civil. El pago de lo no debido y otros supuestos de su procedencia (Santiago, Thomson Reuters).

Barrientos Zamorano, Marcelo (2008): "El sistema indemnizatorio del triple cómputo en la Ley de Propiedad Industrial”, Revista Ius et Praxis, Año 14, Nº 1: pp. 123-143.

Barros Bourie, Enrique (2006): Tratado de Responsabilidad Extracontractual (Santiago, Editorial Jurídica de Chile).

Barros Bourie, Enrique (2009): "Restitución de ganancias por intromisión en derecho ajeno, por incumplimiento contractual y por ilícito extracontractual”, en Morales, Antonio et al. (edits.), Derecho de daños (Madrid, Fundación Coloquio Jurídico Europeo) pp. 11-78.

Basozábal Arrué, Xabier (1997): "Método triple de cómputo del daño: La indemnización del lucro cesante en las leyes de protección industrial e intelectual”, Anuario de Derecho Civil, Tomo L, Fasc. III: pp. 1263-1299.

Basozábal Arrué, Xabier (1998): Enriquecimiento injustificado por intromisión en derecho ajeno (Madrid, Civitas).

BeCh SERRAT, Josep Maria (2018): Sistema de restitución ante un enriquecimiento por mejora (Madrid, Aranzadi).

Bernet PÁez, Manuel Antonio (2007): "El deber de lealtad de los directores y los contratos en conflicto de interés", Revista Chilena de Derecho Privado, No 8: pp. 107-153.

BIRKS, Peter (1985): An Introduction to the Law of Restitution (Oxford, Clarendon Press).

Birks, Peter (1999): "Restitution for Wrongs", en Schrage, Eltjo J.H., Unjust Enrichment. The Comparative Legal History of the Law of Restitution (Berlin, Duncker \& Humboldt, segunda edición) pp. 171-195. 
BIRKs, Peter (2005): Unjust Enrichment (Oxford, Oxford University Press, segunda edición).

Burrows, Andrew (2007): The Law of Restitution (Oxford, Oxford University Press, tercera edición).

Carrasco Perera, Angel (1987): "Restitución de provechos (I)”, Anuario de Derecho Civil (1987), Fascículo 4: pp. 1055-1148.

Claro Solar, Luis (1932): Explicaciones de Derecho Civil Chileno y Comparado, Vol. III (Santiago, Editorial Jurídica de Chile).

Corral Talciani, Hernán (2013): Lecciones de Responsabilidad Extracontractual (Santiago, LegalPublishing, segunda edición).

Dannemann, Gerhard (2009): The German Law of Unjustified Enrichment. A Comparative Introduction (Oxford, Oxford University Press).

Descheemaeker, Eric (2017): "El nuevo derecho francés del enriquecimiento injustificado", en Del Olmo García, Pedro y Basozábal Arrué, Xabier (edits.), Enriquecimiento injustificado en la encrucijada: Historia, derecho comparado y propuestas de modernización (Navarra, Aranzadi) pp. 121-167.

Díez Picazo y Ponce de León, Luis (2011): La doctrina del enriquecimiento sin causa (Bogotá, Depalma).

Domínguez Águila, Ramón H. (2009): "Sobre el artículo 2316 inciso segundo del Código Civil y la acción contra el que recibe provecho del dolo ajeno", Revista de Derecho Universidad de Concepción, No 225-226: pp. 217-230.

Edelman, James (2002): Gain-Based Damages. Contract, Tort, Equity and Intellectual Property (Oxford, Hart Publishing).

Fueyo LANeri, Fernando (1990): Instituciones de Derecho civil moderno (Santiago, Editorial Jurídica de Chile).

GonzÁlez GonzÁlez, Manuel (2017): “Construcción en suelo ajeno a ciencia y paciencia del dueño del terreno: Una aproximación dogmática al inciso segundo del artículo 669 del Código Civil”, Revista Chilena de Derecho Privado, N² 28: pp. 221-269.

Krebs, Thomas (2006): “The Fallacy of 'Restitution for Wrongs", en Burrows, Andrew y Rodger of Earlsferry, Lord (edits.), Mapping the Law. Essays in Memory of Peter Birks (Oxford, Oxford University Press) pp. 379-399.

Momberg Uribe, Rodrigo (2015): “Disgorgement of Profits in Chilean Private Law”, en Hondius, Ewoud y Janssen, André (edits.), Disgorgement of Profits. Gain-Based Remedies throughout the World (Cham, Springer) pp. 459-467.

Momberg Uribe, Rodrigo (2017): "Restitución de ganancias por incumplimiento contractual”, en AA.VV, Estudios de Derecho Civil XII (Santiago, Thomson Reuters) pp. 419-432.

Morales Moreno, Antonio-Manuel (2011): “¿Es posible construir un sistema precontractual de remedios? Reflexiones sobre la Propuesta de modernización del derecho de obligaciones y contratos en el marco del Derecho europeo", en Albiez Dohrmann, Klaus Jochen et al. (coords.), Derecho privado europeo y modernización del Derecho contractual en España (Barcelona, Atelier) pp. 400-422.

Orozco Muñoz, Martín (2015): El enriquecimiento injustificado (Navarra, Thomson Reuters Aranzadi). 
Peñailillo Arévalo, Daniel (1996): "El enriquecimiento sin causa. Principio de derecho y fuente de obligaciones", Revista de Derecho U. de Concepción, N² 200: pp. 7-40.

Peñailillo Arévalo, Daniel (2003): Obligaciones. Teoría general y clasificaciones, la resolución por incumplimiento (Santiago, Editorial Jurídica de Chile).

Peñailillo Arévalo, Daniel (2006): Los Bienes: la propiedad y otros derechos reales (Santiago, Editorial Jurídica de Chile).

Pino EmHart, Alberto (2015): "Sobre la (des)proporcionalidad de la acción indemnizatoria”, Revista de Derecho, Escuela de Postgrado, Vol. 8: pp. 207-220.

Pino EMHART, Alberto (2016): "La restitución de ganancias ilícitas y la acción del provecho por dolo ajeno", Revista Ius et Praxis, Año $22 \mathrm{~N}^{\circ}$ 1: pp. 227-270.

Pino EMHART, Alberto (2018): "La acción restitutoria a favor del Fisco por uso de información privilegiada. El artículo 172 inciso $3^{\circ}$ de la Ley de Mercado de Valores", en AA.VV, Estudios de Derecho Comercial. Octavas Jornadas Chilenas de Derecho Comercial (Santiago de Chile, Thomson Reuters) pp. 505-524.

Pizarro Wilson, Carlos (2009): “La acción de restitución por provecho de dolo ajeno", en AA.VV, Estudios de Derecho Civil IV (Santiago, LexisNexis) pp. 679-688.

Prado López, Pamela (2018): "La restitución de mayores ganancias en el incumplimiento eficiente: una respuesta desde el derecho chileno de los contratos", Revista Ius et Praxis, Año 24, No 3: pp. 335-378.

Ramos Pazos, René (1985): "Edificación en Sitio Ajeno sin Previo Contrato: En torno al artículo 669 del Código Civil”, Revista de Derecho Universidad de Concepción, No 178: pp. 141-147.

Ripstein, Arthur (2007): “As If It Had Never Happened”, William and Mary Law Review, Vol. 48: pp. 1957-1997.

Salah Abusleme, María Agnes (2004): Responsabilidad por uso de información privilegiada en el mercado de valores (Santiago, LexisNexis).

Vergara Bezanilla, José Pablo (1987): "Sujetos pasivos de la acción reivindicatoria (casos contemplados en los arts. 898 y 900 del C. Civil)", Gaceta Jurídica, N 83: pp. 3-14.

Vidal Olivares, Álvaro (2011): "Responsabilidad civil de los directores de sociedades anónimas. Bases para la construcción de un sistema unitario”, en Corral Talciani, Hernán et al. (coords.), Estudios de Derecho Civil. Responsabilidad extracontractual (Santiago de Chile, Abeledo-Perrot): pp. 161-190.

VIRGO, Graham (2015): The Principles of the Law of Restitution (Oxford, Oxford University Press, tercera edición).

von Caemmerer, Ernest (1968): Gesamelte Schriften, Tomo I (Tübingen, J.C.B. Mohr).

Zimmermann, Reinhard (1990): The Law of Obligations. Roman Foundations of the Civilian Tradition (Oxford, Oxford University Press).

Zimmermann, Reinhard y Du Plessis, Jacques (1994): "Basic Features of the German Law of Unjustified Enrichment”, Restitution Law Review, Vol. 2: pp. 14-43.

Zumaquero Gil, Laura (2017): "El enriquecimiento injustificado en el Derecho Privado Europeo”, InDret, N²: pp. 1-53. 


\section{JURISPRUDENCIA CITADA}

Estados Unidos: EDWARDS V. LEE'S ADMINISTRATOR. Court of Appeals of Kentucky, 5 de junio de 1936, 96 S.W. 2d 1028.

Reino Unido: Wrotham Park Estates Ltd. v. Parkside Homes Ltd. Chancery Division, 19 de octubre de 1973, [1974] 1 WLR 798.

FROHLICH CON DIETZ (2002): Corte Suprema, 11 de abril de 2002 (casación en la forma y el fondo) en WestLaw, Código de búsqueda CL/JUR/3215/2002.

CISTERNAS CON LOREN (2012): Corte Suprema, 14 de noviembre de 2012 (casación en el fondo) en WestLaw, Código de búsqueda CL/JUR/2595/2012.

CORFO CON ENERGAS S.A. (2013): Corte Suprema, 30 de septiembre de 2013 (restitución de lo obtenido por provecho del dolo ajeno) en Poder Judicial Rol No 4871-2012.

Corfo con I. Municipalidad de La Pintana (2013): Corte Suprema, 30 de enero de 2013 (restitución de lo obtenido por provecho del dolo ajeno) en Poder Judicial, Rol No 6302-2010.

Astudillo con Compañáa Minera Teck Quebrada Blanca S.A. (2014): Tribunal Constitucional chileno, Rol N² 2437-13-INA, 14 de enero de 2014.

Astudillo con Codelco (2014): Tribunal Constitucional chileno, Rol No 2365-12-INA, 14 de enero de 2014.

BAT CON CORFo (2018): Tribunal Constitucional chileno, Rol N²985-16-INA, 12 de abril de 2018.

Sociedad Corral y Alcaino con Codelco Chile (2015): Corte Suprema, 18 de agosto de 2015 (casación en el fondo y forma) en WestLaw, Código de búsqueda CL/ JUR/4701/2015.

FisCo DE ChILE CON EBEN ARESTi (2016): Corte Suprema, 3 de mayo de 2016 (casación en el fondo) en Poder Judicial, Rol No 19.676-2015.

Fisco de Chile con IRARRÁzabal URETA (2016): Corte Suprema, 21 de julio de 2016 (casación en el fondo) en WestLaw, Código de búsqueda CL/JUR/5142/2016.

Rojas CON Díaz (2016): Corte Suprema, 2 de junio de 2016 (casación en el fondo) en WestLaw, Código de búsqueda CL/JUR/3594/2016.

\section{NORMAS CITADAS}

Código Civil de Francia (21/3/1804).

Código Civil de Chile (22/11/1855).

Código Civil de Alemania (1/1/1900).

Código Civil y Comercial de Argentina (7/10/2014).

Ley $N^{\circ} 17.336$ (2/10/1970), Ley de Propiedad Intelectual.

LeY N 18.045 (22/10/1981), Ley de Mercado de Valores.

LEY N 18.046 (22/10/1981), Ley sobre Sociedades Anónimas.

LeY N 19.039 (25/1/1991), Ley de Propiedad Industrial.

LEY N 20.382 (20/10/2009), Introduce perfeccionamientos a la normativa que regula los gobiernos corporativos de las empresas. 